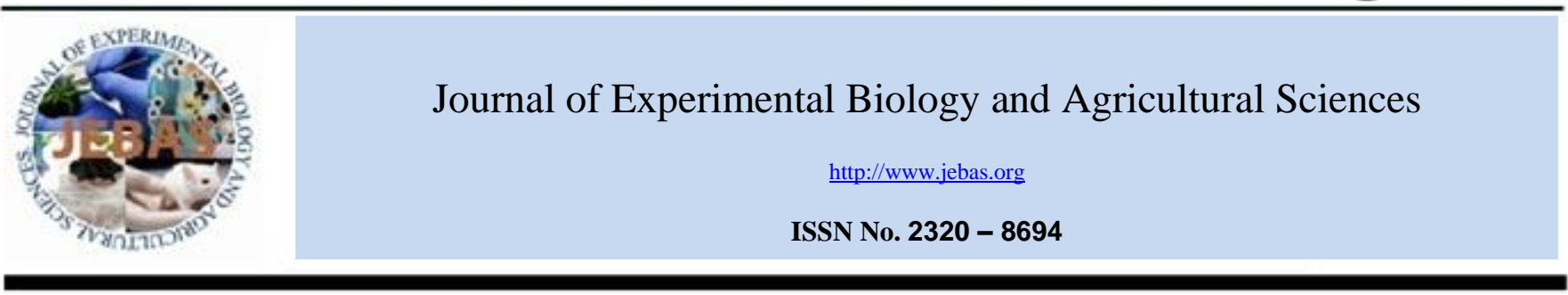

\title{
LEPTOSPIROSIS IN HORSES: SPECIAL REFERENCE TO EQUINE RECURRENT UVEITIS
}

\section{Sandip Kumar Khurana ${ }^{1, *}$, Kuldeep Dhama ${ }^{2}$, Minakshi $\mathrm{P}^{3}$, Baldev Gulati ${ }^{1}$, Yashpal Singh Malik ${ }^{2}$ and Kumaragurubaran Karthik ${ }^{4}$}

${ }^{1}$ NRCE, Hisar, Haryana, India

${ }^{2}$ Indian Veterinary Research Institute, Izatnagar, Barrielly, U.P., India

${ }^{3}$ Department of Animal Biotechnology, LUVAS, Hisar, Haryana, India

${ }^{4}$ Tamil Nadu University of Veterinary and Animal Sciences, Chennai, Tamil Nadu, India

Received - August 27, 2016; Revision - September 04, 2016; Accepted - October 03, 2016

Available Online - December 04, 2016

DOI: http://dx.doi.org/10.18006/2016.4(Spl-4-EHIDZ).S123.S131

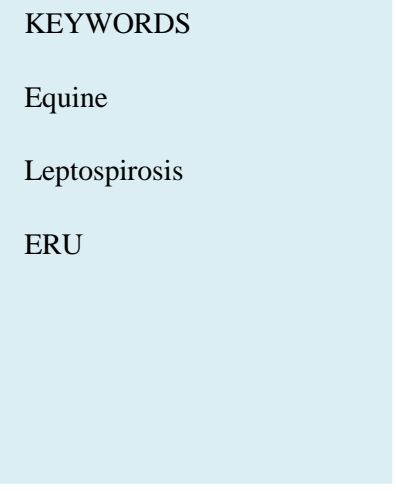

\begin{abstract}
Leptospirosis is a bacterial zoonotic disease with worldwide distribution. The disease affects several domestic and wild animals. Leptospirosis has seasonal nature with high incidence in hot rainy season especially in tropical regions. The disease in horses has ocular and systemic manifestations. However, stillbirths and neonatal mortality due to this disease is also common. The ocular manifestation is equine recurrent uveitis (ERU), also known as periodic ophthalmia or moon blindness, where autoimmune mechanisms also play an important role. Several diagnostic assays are employed and microscopic agglutination test has been commonly employed in several parts of the world though isolation is the gold standard test. Recent diagnostic advances like PCR, real time PCR, LAMP also aid in early diagnosis of the disease so that the spread of disease to other animals and human can be prevented.
\end{abstract}

* Corresponding author

E-mail: sandipkk2003@yahoo.co.in (Sandip Kumar Khurana)

Peer review under responsibility of Journal of Experimental Biology and Agricultural Sciences.

Production and Hosting by Horizon Publisher India [HPI] (http://www.horizonpublisherindia.in/).

All rights reserved.
All the article published by Journal of Experimental Biology and Agricultural Sciences is licensed under a Creative Commons Attribution-NonCommercial 4.0 International License Based on a work at www.jebas.org.

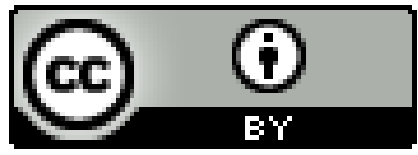




\section{Introduction}

Leptospirosis is a major animal and human health problem worldwide. Leptospires belong to family Leptospiraceae, order spirochaetales. Leptospires are about $0.1 \mu \mathrm{m}$ in diameter and 6-20 $\mu \mathrm{m}$ in length. Their major antigenic component is lipopolysaccharide (LPS). The disease is prevalent in many parts of the world both in urban and rural settings (Vinetz, 1997; Bharti et al., 2003; Verma et al., 2013; Khurana et al., 2015). The leptospirosis primarily causes chronic kidney infection in several domestic and wild animals. The leptospira colonize in renal tubules and are shed in urine. These bacteria survive for prolonged periods in moist conditions and thus transmit the infection.

Rats and other rodents are natural reservoirs of leptospira with no apparent signs of disease. They clear infections from their bodies except the kidney tubules. Other animals which are not natural carriers of infection have mild to severe infection and even death. The leptospires may cause reproductive problems mainly abortions (Coghlan \& Bain, 1969; Faine et al., 1984; Faine et al., 1999; Bharti et al., 2003; Hamond et al., 2015; Hamond et al., 2016). Mother to foetus transmission is also common (Vinetz, 1997; Bharti et al., 2003; Alder \& de la Pena Moctezuma, 2010; Verma et al., 2013; Hamond et al., 2014).

Animal handlers and waste water/ recycle workers are highly susceptible (Campagnolo et al., 2000). Leptospira spp. are endemic to several tropical and subtropical areas affecting military personnel, aid workers, tourists and general public (Ko et al., 1999; Bharti et al., 2003). Leptospirosis is less common in temperate regions. There are different reservoirs of infection in rural and urban areas, domestic and wild animals act as reservoirs in rural settings, dogs and rats are reservoirs in urban areas (Vinetz et al., 1996; Levett, 2001; Meites et al., 2004). Natural disasters, like floods may be followed by leptospirosis outbreaks (Fuortes \& Nettleman, 1994). The leptospirosis has been described as "an occupational disease of soldiers" as the soldiers fighting in adverse terrains and conditions during wars are at a greater risk of acquiring leptospirosis infection (Johnston et al., 1983).

Symptoms in human beings may vary, but commonly include fever, headache, muscular pain, uneasiness, vomiting conjunctivitis, uveitis, meningitis and jaundice. About 5 and $10 \%$ of patients progress to icteric phase. Fatality rates at this stage may be more than $20 \%$. Mortality is primarily due to acute renal failure, pulmonary haemorrhages, intracerebral haemorhage and multisystem organ failure (Vinetz, 1997; Faine et al., 1999; Ko et al., 1999; Levett, 2001; Bharti et al., 2003).

Leptospirosis in horses has been considered a relatively uncommon infection. Most of the infections are asymptomatic. A specific outcome of equine leptospirosis is recurrent uveitis which appears to be mediated by autoimmune mechanisms.

\section{Equine Leptospirosis}

\subsection{Disease occurrence}

The incidence of leptospirosis in horses remains uncertain as systematic studies on leptospirosis in horses are scanty. Its importance and economic impact in equines is also not as accurately distinguished as for other species of animals. Most epidemiological studies are based on serology with highly variable incidence in different geographical regions. There is also variability in the serovars. A sero-prevalence of only $1.5 \%$ was reported in central Italy, for serovars Icterohaemorrhagiae, Bratislava or Pomona (Ebani et al., 2012). However, a Brazilian study of 119 race horses showed a much higher seropositivity rate of $71 \%$ against serovar Copenhageni (Hamond et al., 2012b). All these horses were apparently healthy with no clinical signs of leptospirosis. In another study by the same group, seropositivity of $48 \%$ was reported and $35 \%$ of urine samples were detected positive by PCR, however these were culturally negative (Hamond et al., 2013). Recently a prevalence study conducted in Brazil in 38 mares having reproductive problems examined for leptospira by examining the serum, urine and vaginal fluid by isolation and PCR. Seventeen serum samples were positive (44.7\%) for leptospira and of which sero groups Australis accounts for $76.4 \%$ and Pomona 23.6\%. PCR results were positive for 17 vaginal fluid samples and 10 urine samples and the PCR products were sequenced which showed that the samples belonged to $L$. interrogans (sv Bratislava and Pomona) and $L$. borgpertersenii. Thus this study implies the presence of leptospira in reproductive tract (Hamond et al., 2015). Sixty two cart horse samples were screened in Curitiba, southern Brazil by microscopic agglutination test (MAT) and real time PCR of which $80.8 \%$ of the samples were positive for Icterohaemorrhagiae serovar (Finger et al., 2014).

Sero-positivity of $25 \%$ in Korea with serovars Sejroe and Bratislava being prominent (Jung et al., 2010), 79\% in The Netherlands, serovars Copenhegi and Bratislava (Houwers et al., 2011) and 25\% in Sweden (Baverud et al., 2009) show marked differences in prevalence and varied serovars according to geographical region. It was also indicated that the majority of equine infections were asymptomatic. A North American report in aborting mares revealed 20 out of 21 as due to serovar Pomona subtype Kennewicki (Timoney et al., 2011), which is correlated to the presence of this serovar and subtype in local wildlife mainly raccoons. Serovar Bratislava has been implicated in horses in Northern Ireland, based on culture and serology (Ellis et al., 1983). Pikalo et al. (2016) examined the presence of leptospiral antibodies in horses in middle Germany by MAT. 54 out of 314 (17.2\%) horses were positive for one or more of eight leptospiral serovars analysed. Icterohaemorrhagiae $(11.1 \%)$ was most prevalent followed by Bratislava (9.6\%) and Grippotyphosa (1.9\%). Dorrego-Keiter et al. (2016) detected 57.5\% (127/221) horses with ERU having antibodies against leptospira by MAT in Germany. 


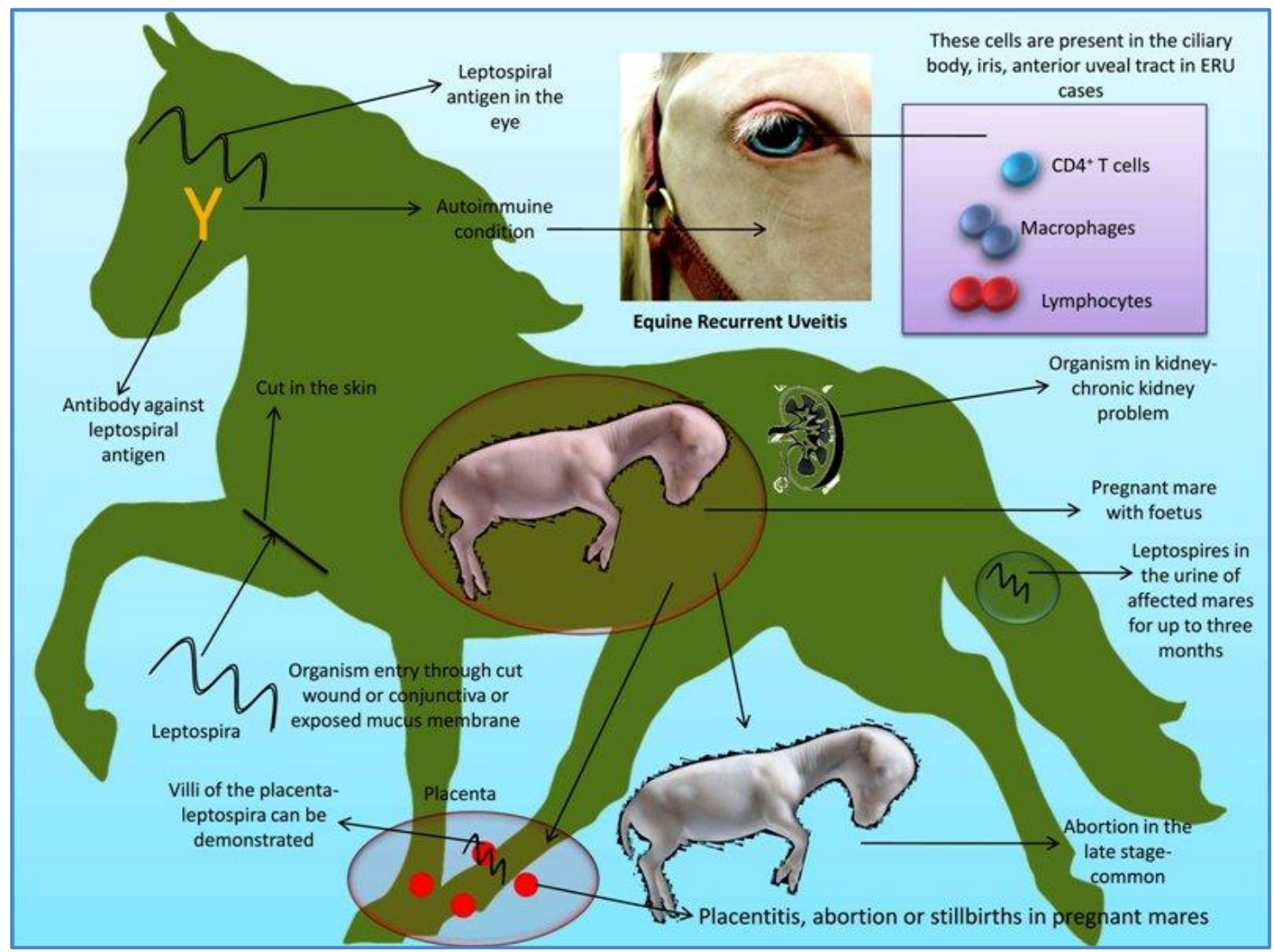

Figure 1Transmission and clinical signs of equine leptospirosis.

The most frequent antibodies were against Grippotyphosa (79/127), followed by Icterohaemorrhagiae (34/127) and Bratislava (29/127). Tsegay et al. (2016) detected significant antibody titres in 184 of 418 carthorses to at least one of 16 serovars of Leptospira species in central and southern Ethiopia. Serovar Bratislava (34.5\%) was found to be most prevalent.

National Reference Centre for Leptospirosis (NRCL) of Italy along with other units evaluated the occurrence and distribution of leptospira in Italy. Analysis of the data for the one year (2010-2011) revealed that Australis was common among horses in Italy (Tagliabue et al., 2016).

Khurana et al. (2003) studied the sero-prevalence of leptospira in 436 equines in India by ELISA for detection of antibodies against six leptospiral serovars including Leptospira interrogans serovars Canicola, Pomona, Australis, Autumnalis, Icterohaemorrhagiae and Grippotyphosa. These samples included 379 serum samples from apparently healthy equines, 12 from cases of abortion and 45 from equines in contact with aborted animals. Out of the 379 apparently healthy horses, 64 (16.89\%) harboured antibodies against Leptospira spp. They further reported the mares that came into contact with aborted animals, $66.7 \%$ had positive titres indicative of leptospiral infection. Animals in contact with aborted animals had also showed higher sero-prevalence of $64.4 \%$. Antibody titres in apparently healthy animals suggest either a subclinical form of the disease in these animals or previous infection. Region-wise sero-prevalence of leptospiral antibodies showed that studs in southern and western part of India country had higher seropositivity irrespective of the group.

\subsection{Clinical signs, symptoms and disease manifestations}

Equine leptospirosis is accompanied with mild fever. Loss of appetite and lethargy are common in mild form of disease. Jaundice, haemorrhages on the mucosa and depression are predominant signs in the severe form. Renal failure is more common in foals in comparison to old horses. Classic icteric leptospirosis occurs mainly in foals and is comparatively rare in adult horses. Leptospirosis may cause placentitis, abortions and stillbirths in pregnant mares (Figure 1) (Timoney et al., 2011). The letospires could be seen in foetal and maternal tissues, microscopically (Poonacha et al., 1993). Leptospiral abortions in the late stage of gestation, with no apparent clinical signs are common. Weak and icteric foals are also born (Donahue et al., 1991; Donahue et al., 1995). Infected mares shed leptospires in the urine for prolonged periods and transmit the infection (Donahue \& Williums, 2000; Newman \& Donahue, 2007). 
Microscopically placental lesions include vasculities, thrombosis, inflammatory cells in the stroma and villi, cystic adenomatous hyperplasia of allantoic epithelium. Foetal liver and kidneys are enlarged. Microscopic lesions in foetus include suppurative and nonsuppurative nephritis, leukocytic infiltration of the portal triads, giant cell hepatopathy, pulmonary haemorrhages, pneumonia and myocarditis (Wilkie et al., 1988; Poonacha et al., 1993). Histopathological findings in young horses are marked with petechiae and lymphoytic infiltration in renal proximal tubules and glomeruli (Bernard, 1993; Faine et al., 1999). Equine recurrent uveitis is a common sequel in equines, which is dealt separately in this review.

The pulmonary haemorrhage is not common in equines (Bharti et al., 2003). Recently this syndrome is being reported more commonly than previous information (Broux et al., 2012) and endoscopy revealing pulmonary haemorrhage in $35 \%$ of seropositive adult horses (Hamond et al., 2012a).

\subsection{Diagnosis of leptospirosis in equines}

The diagnosis of leptospirosis in horses is similar to that for other species. The gold standard is the culture and identification of leptospira. PCR is a more convenient and rapid (Alder \& de la Pena Moctezuma, 2010). Real time PCR assay was recently compared with fluorescent antibody test (FAT) and microscopic agglutination test (MAT) for effective diagnosis of equine leptospirosis from foetal specimens like placenta, kidney, liver and heart blood. Out of the 21 confirmed cases of equine abortion real time PCR could detect all the positives correctly while MAT and FAT detected only 19 and 18 samples respectively. Thus qPCR is a better assay compared to MAT and FAT for diagnosis of leptopsiral abortion in equines (Erol et al., 2015). Silver staining and FAT may be used to demonstrate leptospires in the placenta or foetal kidney. FAT is more sensitive than silver staining and more specific than MAT (Donahue \& Williams, 2000; Szeredi \& Haake, 2006; Newman \& Donahue, 2007). Enzyme-linked immunosorbent assay (ELISA) has also been developed using different proteins of leptospira and its efficacy has been assessed time to time. Recently a cocktail of recombinant proteins namely rLipL21, rLoa22, rLipL32, and rLigACon4-8 of Leptospira interrogans were analyzed for its potential as a diagnostic marker through ELISA. The assay was tested with 130 serum samples and the results were compared with MAT and it was found that ELISA was sensitive and specific yielding similar results with MAT assay (Ye et al., 2014).

MAT is the test of choice for serological diagnosis. In an endemic area the value of a single positive specimen is limited. The four-fold rise in titre in paired sera is important for accurate diagnosis. In cases of leptospiral abortion, MAT on foetal fluids and maternal serum gives a very high titre indicative of positive diagnosis (Donahue \& Williams, 2000). Serological tests in different areas should include prevalent serovars of that area as test antigens. Commercial enzyme immunoassays incorporating locally prevalent serovars are available.
2.4 Prevention and control

Treatment regimens for horses have mostly been derived by extrapolation from other species, due to non availability of specific information for horses. Streptomycin and penicillin are most common antibiotics of choice. Tetracyclines are used as an alternative. The penicillin dose is related to titre of leptospiral antibodies. The streptomycin is has severe toxic effects in horses (Bernard 1993; Newman \& Donahue, 2007).

Till now there were no leptospirosis vaccine for horses. Cattle vaccines were being occasionally used in horses, which is not advisable. In leptospiral uveitis molecular mimicry occurs between leptospiral proteins and ocular tissues, in this situation vaccination with whole-cell bacterin may prime equines with cross-reacting antigens resulting in stronger immunological responses and development of eye inflammation in subsequent exposures. Ideally, proposed leptospirosis vaccine should be free of cross-reacting antigens. Several leptospiral antigens have been tested for protective efficacy (Alder \& de la Pena Moctezuma, 2010; Murray et al., 2013). No antigen has been tested in horses. Recently, Zoetis has introduced a licensed equine leptospiral vaccine for prevention of leptospirosis caused by Leptospira Pomona. Prevention must therefore revolve around normal husbandry and hygiene practices, vaccination of other animals on the farm, minimizing contact with rodents and other wildlife carriers and other infected horses.

\section{Equine Recurrent Uveitis (ERU)}

A major consequence of leptospirosis in horses is uveitis or moon blindness also called periodic ophthalmia (Verma et al., 2013; Malalana et al., 2015). The uvea consists of three components, the iris, ciliary body (anterior uvea) and choroid (posterior uvea). The uveal tract is highly vascular, usually pigmented (Samuelson, 2007; Gilger \& Deeg, 2011: Hollingsworth, 2011). Direct proximity to the peripheral vasculature, makes the uveal tract vulnerable to any disease of the systemic circulation (Hughes, 2010; Leiva et al., 2010; Gilger \& Deeg, 2011). A blood-ocular barrier exists between the peripheral vasculature and the inner structures of the eye, divided into the blood-aqueous barrier (iris and ciliary body) and blood-retinal barrier (choroid). These barriers make the eye a protected or immune-privileged site. Disruption of this barrier allows the leakage of blood products and cells into the eye and the activation of several immune responses. Leptospira-associated uveitis forms an important part of ERU cases (Halliwell et al., 1985; Hartskeerl et al., 2004; Witkowski et al., 2016). ERU is inflammation of uvea which occurs recurring episodes (Cook \& Harling, 1983). It is reported to have a worldwide prevalence of around $10 \%$ and thought to be a major cause of blindness in horses (Schwink, 1992; Hartskeerl et al., 2004).

Pathogenesis of ERU is not exactly elucidated though several possible ways has been reported. Eye of horses affected with ERU shows infiltration of macrophages, lymphocytes and 
plasma cells into the ciliary body and also the iris. This shows that immunologically privileged sites wall has been breached by the organism. There is huge flow of $\mathrm{CD} 4^{+} \mathrm{T}$ lymphocytes in the anterior uveal tract (Romeike et al., 1998). In these affected horses $\mathrm{T}$ cell response is mainly of Th1 based (Gilger et al., 1999). Kalsow et al. (1994) reported that T- and B-cells are highly organized in the germinal centres in the horses affected with ERU. This highly organized structure shows the antibody response towards leptospira antigen in the anterior uvea (Kalsow et al., 1994). Leptospira can directly cause damage to the eye leading to ERU but mainly it is caused by the autoimmune response due to the antigen (Verma et al., 2005). Two leptopsiral proteins namely LruA and LruB were suggested to play a major role in ERU since IgG and IgA specific for these proteins has been identified in the fluid from the eye (Verma et al., 2005). Hence these proteins can also be used as a diagnostic marker for detection of leptospiral infection in equines. An evidence of a antigenic relationship between Leptospira and equine eye is established further cross reactivity as a mechanism of disease progression has been proposed (Parma et al., 1985; Parma et al., 1987; Parma et al., 1997). Verma et al. (2005) described that intraocular expression of two leptospiral proteins, LruA and LruB antibodies was significantly higher than in the sera, indicating local production and antibodies in uveitic eyes. The lens proteins cross-reacting with LruA antiserum were identified as crystalline $\mathrm{B}$ and vimentin, and cross reacting retinal protein was identified as crystalline B2 (Verma et al., 2010). Therefore cross reactivity between leptospiral and ocular proteins may be responsible for immunopathogenesis of ERU of leptospirai origin.

ERU has three distinct clinical forms: classic, insidious and posterior (Gilger \& Michau, 2004; Gilger \& Deeg, 2011; Malalana et al., 2015). Classic ERU is characterised by active intraocular inflammation followed by quiet periods, where subsequent inflammatory phases show increased severity. Insidious ERU is characterised by low grade persistent inflammation. The Vitreous, choroid and retina are primarily affected in posterior uveitis.

The signs associated with an acute episode of anterior uveitis are varied including ocular pain, blepharospasm, lacrimation, chemosis, photohobia, oedema of the eyelid, swollen conjunctiva and corneal oedema, aqueous flare, hypopyon, hyphaema, miosis, iris colour changes and low intraocular pressure (Cook et al., 1983: Wada, 2006; Gilger \& Deeg, 2011). Posterior uveitis is characterised by vititis with liquefaction of the vitreous and retinal changes.

Changes associated with previous episodes of uveitis in an otherwise quiescent eye may give clues to previous episodes. Some of these changes may include depigmentation, corneal scarring, atrophy and fibrosis of iris, abnormalities of the iris margin, cataract, glaucoma and fundic changes etc. (Williams et al., 1971) but are not specifically pathognomonic (Cook et al., 1983; Barnett, 1987; Spiess, 2010; Mathes et al., 2012). The prognosis is dependent on an early diagnosis and treatment. A period of low inflammation follows the acute phase (Cook \& Harling, 1983). Secondary cataract, anterior or posterior attachment of iris, lens luxation, vitreous exudates and retinal detachment are also witnessed due to severe inflammatory reaction (Rebhun, 1979; Cook \& Harling, 1983; Gilger et al., 2000; Gilger \& Michau, 2004). A pathognomonic sign of ERU is thick hyaline membrane near posterior aspect of iris and eosinophilic linear cytoplasmic inclusion bodies in nonpigmented ciliary epithelial cells (Cooley et al., 1990; Dubielzig et al., 1997).

ERU has been associated with sulphonamides administration or vaccination (Matthews \& Handscombe, 1983; Whitcup, 2010). Higher prevalence in geldings compared to mares and stallions has been reported (Szemes \& Gerhards, 2000). No particular sex related differences in prevalence have been reported (Gilger \& Deeg, 2011; Kulbrock et al., 2013). Age of presentation has been reported to vary in different studies (Dwyer et al., 1995; Szemes \& Gerhards, 2000).

Diagnosis of Leptospira associated ERU is based on the presence of classical signs of uveitis, history of recurrence and seropositivity by MAT. No specific test is available for the diagnosis of leptospiral uveitis. Negative MAT titres are not always indicative of absence of leptospiral infection.

Reducing inflammation is of primary concern in ERU therapy. An intraocular device containing cyclosporine $\mathrm{A}$ is found effective in treatment of leptospiral ERU (Werry \& Gerhards, 1991; Gilger \& Michau, 2004). However, usefulness of antibiotics in treating ERU has not been fully explored. A recent review conducted in the North Carolina State University Veterinary Health Complex with the medical records of ERU from 1999 to 2014 showed that most cases had blindness, eye globe loss and loss of eye function. Several owners opted for euthanasia and some opted to sell the animals due to recurrent eye problem (Gerding \& Gilger, 2016). Thus this problem of ERU has caused great financial loss to the horse owners.

Thus leptospiral infections result in reproductive and respiratory problems in equines. However, the most important manifestation of leptospiral infection in equines is ERU, which affects equine population by causing blindness, thus rendering them useless. Therefore more researches are needed to explore the pathogenesis and mechanism of occurrence of ERU with an aim of its prevention and control.

\section{Conflict of interest}

Authors would hereby like to declare that there is no conflict of interests that could possibly arise.

\section{References}

Adler B, de la Pena Moctezuma A (2010) Leptospira and leptospirosis. Veterinary Microbiology 140: 287-296. doi: 10.1016/j.vetmic.2009.03.012. 
Barnett KC (1987) Equine periodic opthalmia: A continuing aetiological riddle. Equine Veterinary Journal 19: 90-91.

Baverud V, Gunnarsson A, Engvall EO, Franzen P, Egenvall A (2009) Leptospira seroprevalence and associations between seropositivity, clinical disease and host factors in horses. Acta Veterinaria Scandinavica 51:15. doi: 10.1186/1751-0147-5115

Bernard WV (1993) Leptospirosis. The Veterinary Clinics of North America, Equine Practice 9: 435-444.

Bharti AR, Nally JE, Ricaldi JN, Matthias MA, Diaz MM, Lovett MA, Levett PN, Gilman RH, Wiling MR, Gotuzzo E, Vinetz JM (2003) Leptospirosis: a zoonotic disease of global importance. The Lancet, Infectious Diseases 3: 757-771.

Broux B, Torfs S, Wegge B, Deprez P, van Loon G, (2012) Acute respiratory failure caused by Leptospira spp. in 5 foals. Journal of Veterinary Internal Medicine 26: 684-687.

Campagnolo E, Warwick M, Marx H, Cowart R, Donnell H, Bajani M, Bragg S, Esteban J, Alt D, Tappero J, Bolin C, Ashford D (2000) Analysis of the 1998 outbreak of leptospirosis in Missouri in humans exposed to Infected swine. Journal of American Veterinary Medical Association 216: 676682.

Coghlan JD, Bain AD (1969) Leptospirosis in human pregnancy followed by death of the foetus. British Medical Journal 1: 228-230.

Cook CS, Harling DE (1983) Equine recurrent uveitis, Equine Veterinary Journal 2: 2-15.

Cook CS, Peiffer RL, Harling DE (1983) Equine recurrent uveitis. Equine Veterinary Journal 15: 57-60.

Cooley PL, Wyman M, Kindig O (1990). Pars plicata in equine recurrent uveitis. Veterinary Pathology 27: 138-140. doi: $10.1177 / 030098589002700215$

Donahue JM, Smith BJ, Poonacha KB, Donahoe JK, Rigsby CL (1995) Prevalence and serovars of Leptospira involved in equine abortions in central Kentucky during the 1991-1993 foaling seasons. Journal of Veterinary Diagnostic Investigation 7: 87-91. doi: 10.1177/104063879500700114

Donahue JM, Smith BJ, Redmon KJ, Donahue JK (1991) Diagnosis and prevalence of leptospira infection in aborted and stillborn horses. Journal of Veterinary Diagnostic Investigation 3: $148-151$.

Donahue JM, Williams NM (2000) Emergent causes of placentitis and abortions. The Veterinary Clinics of North America, Equine Practice 16: 443-456.
Dorrego-Keiter E, Toth J, Dikker L, Sielhorst J, Schusser GF (2016) Detection of leptospira by culture of vitreous humor and detection of antibodies against leptospira in vitreous humor and serum of 225 horses with equine recurrent uveitis. Berl Munch Tierarztl Wochenschr. 129 : 209-215.

Dubielzig RR, Render JA, Morreale RJ (1997) Distinctive morphologic features of the ciliary body in equine recurrent uveitis. Veterinary and Comparative Opthalmology 7: 163167.

Dwyer AE, Crockett RS, Kalsow CM (1995) Association of leptospiral seroreactivity and breed with uveitis and blindness in horses-372 cases (1986-1993). Journal of the American Veterinary Medical Association 207: 1327-1331.

Ebani VV, Bertelloni F, Pinzauti P, Cerri D (2012) Seroprevalence of Leptospira spp. and Borrelia burgdorferi sensu lato in Italian horses. Annals of Agricultural and Environmental Medicine 19: 237-240.

Ellis WA, O'Brien JJ, Cassells JA, Montgomery J (1983) Leptospiral infection in horses in Northern Ireland: serological and microbiological findings. Equine Veterinary Journal 15: 317-320.

Erol E, Jackson CB, Steinman M, Meares K, Donahoe J, Kelly N, Locke S, Smith JL, Carter CN (2015) A diagnostic evaluation of real-time PCR, fluorescent antibody and microscopic agglutination tests in cases of equine leptospiral abortion. Equine Veterinary Journal 47 : 171-4.

Faine S, Adler B, Bolin C, Perolat P (1999) Leptospira and leptospirosis 2nd edition. Melbourne, Australia: MedSci. ISBN $095863260 \mathrm{X}$

Faine S, Adler B, Christopher W, Valentine R (1984) Fatal congenital human leptospirosis. Zentralblatt fur Bakteriologie Mikrobiologie und Hygiene I Abteilung Originale A 257.548.

Finger MA, de Barros Filho IR, Leutenegger C, Estrada M, Ullmann LS, Langoni H, Kikuti M, Dornbush PT, Deconto I, Biondo AW (2014). Serological and molecular survey of Leptospira spp. among cart horses from an endemic area of humanleptospirosis in Curitiba, southern Brazil. Revista do Instituto de Medicina Tropical de Sao Paulo 56 : 473-6.

Fuortes L, Nettleman M (1994) Leptospirosis: a consequence of the lowa flood. lowa Medicine 84: 449-450.

Gerding JC, Gilger BC (2016) Prognosis and impact of equine recurrent uveitis. Equine Veterinary Journal $48: 290-8$.

Gilger BC, Malok E, Cutter KV, Stewart T, Horohov DW, Allen JB (1999) Characterization of T-lymphocytes in the anterior uvea of eyes with chronic equine recurrent uveitis. Veterinary Immunology and Immunopathology 77: 17-28. 
Gilger BC, Malok E, Stewart T, Horohov DW, Ashton P, Smith T, Jaffe GJ, Allen JB (2000) Effect of an intravitreal cyclosporine implant on experimental uveitis in horses. Veterinary Immunology and Immunopathology 76: 239-255.

Gilger BC, Michau TM (2004) Equine recurrent uveitis: new methods of management. The Veterinary Clinics of North America, Equine Practice 20: 417-427.

Gilger BC, Deeg C (2011) Equine recurrent uveitis. In: Gilger BC (Ed.), Equine Ophthalmology, Second Ed. Elsevier Saunders, Maryland Heights, MO, USA. pp. 317-349.

Halliwell RE, Brim TA, Hines MT, Wolf D, White FH (1985) Studies on equine recurrent uveitis. II. The role of infection with Leptospira interrogans serovar Pomona. Current Eye Research 4: 1033-1040.

Hamond C, Martins G, Lawson-Ferreira R, Medeiros MA, Lilenbaum W (2013) The role of horses in the transmission of leptospirosis in an urban tropical area. Epidemiology and Infection 141: 33-35. doi: 10.1017/S0950268812000416.

Hamond C, Martins G, Lilenbaum W (2012a) Pulmonary hemorrahage in horses seroreactive to leptospirosis in Rio de Janeiro, Brazil. Journal of Veterinary Internal Medicine 26: 1237. doi: 10.1111/j.1939-1676.2012.01020.x

Hamond C, Martins G, Lilenbaum W (2012b) Subclinical leptospirosis may impair athletic performance in racing horses. Tropical Animal Health and Production 44: 1927-1930. doi: 10.1007/s11250-012-0158-5.

Hamond C, Pinna A, Martins G, Lilenbaum W (2014) The role of leptospirosis in reproductive disorders in horses. Tropical Animal Health and Production 46: 1-10. doi: 10.1007/s11250013-0459-3.

Hamond C, Pestana CP, Rocha-de-Souza CM, Cunha LE, Brandao FZ, Madeiros MA, Lilenbum W (2015) Presence of leptospirosis on genital tract of mares with reproductive problems. Veterinary Microbiology 179 : 264-269. doi: 10.1016/j.vetmec.2015.06.014.

Hamond C, Martins G, Bremont S, Madeiros MA, Bourhy P, Lilenbum W (2016) Molecul;ar characterization and serology of Leptospira kirschneri (serogroup Grippotyphosa) isolated from urine of a mare post-abortion in Brazil. Zoonoses and Public Health 63: 191-195. doi: 10.1011/zph.12224.

Hartskeerl RA, Goris MG, Brem S., Meyer P, Kopp H, Gerhards H, Wollanke B (2004) Classification of Leptospira from the eyes of horses suffering from recurrent uveitis. Journal of veterinary medicine B, Infectious Diseases and Veterinary Public Health 51:110-115.doi.org/10.1111/j.14390450.2004.00740.x
Hollingsworth SR (2011) Diseases of the Uvea. In : Gilger, B.C. (Ed.), Equine Opthalmology, Second Ed. Elsevier Saunders, Maryland Heights, MO, USA, pp. 267-281.

Houwers DJ, Goris MGA, Abdoel T, Kas JA, Knobbe SS, van Dongen AM, Westerduin FE, Klein WR, Hartskeerl RA (2011) Agglutinating antibodies against pathogenic Leptospira in healthy dogs and horses indicate common exposure and regular occurrence of sub-clinical infections. Veterinary Microbiology 148: 449-451.

Hughes KJ (2010) Ocular manifestations of systemic disease in horses. Equine Veterinary Journal 42: 89-96. doi: 10.1111/j.2042-3306.2010.tb05640.x

Johnston J, Lloyd J, McDonald J, Waitkins S (1983) Leptospirosis-an occupational disease of soldiers. Journal of the Royal Army Medical Corps 129: 111-114.

Jung BY, Lee KW, Ha TY (2010) Seroprevalence of Leptospira spp. in clinically healthy racing horses in Korea. Journal of Veterinary Medical Science 72: 197-201. doi: 10.1292/jvms.09-0273

Kalsow C, Turpin L, Dwyer A (1994) Immunopathology of eyes and pineal glands in equine recurrent uveitis. Reg Immunology 6: 14-20.

Khurana SK, Malik P, Nandal A, Srivastava SK (2003) Seroprevalence of leptospirosis in equines in India. Indian Journal of Comparative Microbiology, Immunology and Infectious Diseases 24 : 93-95.

Khurana SK, Dhama K, Prasad M, Karthik K, Tiwari R (2015) Zoonotic pathogens transmitted from equines: diagnosis and control. Advances in Animal and Veterinary Sciences 3: 32-53. doi: 10.14737 journal.aavs/2015/3.2s.32.53

Ko A, Galvao Reis M, Ribeiro Dourado C, Johnson W, Riley L (1999) Urban epidemic of severe leptospirosis in Brazil. Salvador Leptospirosis Study Group. Lancet 354: 820-825.

Kulbrock M, Distl O Ohnesorge B (2013) A review of candidate genes for development of equine recurrent uveitis. Journal of Equine Veterinary Science 33: 885-892.

Leiva M, Pena T, Armengou L, Cesarini C, Monreal L (2010) Uveal inflammation in septic newborn foals. Journal of Veterinary Internal Medicine 24: 391-397.

Levett PN (2001) Leptospirosis. Clinical Microbiology Reviews 14: 296-326. doi: 10.1128/CMR.14.2.296-326.2001

Malalana F, Stylianides A, McGowan C (2015) Equine recurrent uveitis: human and equine perspectives. The Veterinary Journal 206: 22-29 doi: 10.1016/j.tvj1.2015.06.017 
Mathes RL, Burdette EL, Moore PA, Myrna KE (2012) Concurrent clinical intraocular findings in horses with depigmented punctuate chorioretinal foci. Veterinary Ophthalmology 15: 81-85.

Matthews AG, Handscombe MC (1983) Uveitis in the horse: A review of the aetiological and immunopathological aspects of the disease. Equine Veterinary Journal 15: 61-64.

Meites E, Jay M, Deresinski S, Shieh W, Zaki SR, Tompkins L, Smith D (2004) Reemerging leptospirosis, California. Emerging Infectious Diseases 10: 406-412 doi: 10.3201/eid1003.030431

Murray GL, Lo M, Bulach DM, Srikram A, Seemann T, Quinsey NS, Sermswan RW, Allen A, Adler B (2013) Evaluation of 238 antigens of Leptospira borgpetersenii serovar Hardjo for protection against kidney colonisation. Vaccine 31: 495-499. doi: 10.1016/j.vaccine.2012.11.028.

Newman D, Donahue JM (2007) Equine Leptospirosis. Equine Diseases 16: 4-5.

Parma AE, Fernandez AS, Santisteban CG, Bowden RA, Cerone SI (1987) Tears and aqueous humor from horses inoculated with Leptospira contains antibodies which bind to cornea. Veterinary Immunology Immunopathology 14: 181185 .

Parma, AE, Santisteban CG, Villablab JS, Bowden RA (1985) Experimental detection of an antigenic relationship between Leptospira and equine cornea. Veterinary Immunology and Immunopathology 10: 215-224.

Parma AE, Sanz ME, Lucchesi PM, Mazzonelli J, Petruccelli MA (1997) Detection of an antigenic protein of Leptospira interrogans which shares epitopes with the equine cornea and lens. Veterinary Journal 153: 75-79. doi: 10.1016/S10900233(97)80011-1

Pikalo J, Sattler T, Eichinger M, Loitsch A, Sun H, Schmoll F, Schusser GF (2016) Occurence of antibodies against leptospira in horses in Middle Germany. Berl Munch Tierarztl Wochenschr 129 : 202-208.

Poonacha KB, Donahue JM, Giles RC, Hong CB, PetritesMurphy MB, Smith BJ, Swerczek TW, Tramontin RR, Tuttle PA (1993) Leptospirosis in equine foetuses, stillborn foals, and placentas. Veterinary Pathology 30: 362-369.

Rebhun WC (1979) Diagnosis and treatment of equine uveitis. Journal of American Veterinary Medical Association 175: 803808.

Romeike A, Brugmann M, Drommer W (1998) Immunohistochemical studies in equine recurrent uveitis (ERU). Veterinary Pathology 35: 515-526.
Samuelson DA (2007) Ophthalmic anatomy. In: Gelatt KN (Ed.). Veterinary Ophthalmology, Fourth Ed. Blackwell Publishing Ltd. Ames, IA, USA. pp. 62-98.

Schwink KL (1992) Equine uveitis. The Veterinary Clinics of North America, Equine Practice 8: 557-574.

Spiess BM (2010) Equine recurrent uveitis: The European viewpoint. Equine Veterinary Journal 42 (Supp.): 50-56.

Szemes PA, Gerhards H (2000) Study on the prevalence of equine recurrent uveitis in the Cologne-Bonn area. Der Praktische Tierarzt 81: 408-420.

Szeredi L, Haake DA (2006) Immunohistochemical identification and pathologic findings in natural cases of equine abortion caused by leptospiral infection. Veterinary Pathology 43: 755-761.

Tagliabue S, Figarolli BM, D'Incau M, Foschi G, Gennero MS, Giordani R, Giordani R, Natale A, Papa P, Ponti N, Scaltrito D, Spadari L, Vesco G, Ruocco L (2016) Serological surveillance of Leptospirosis in Italy: two year national data (2010 2011). Veteriaria Italiana 52:129-38.

Timoney JF, Kalimuthusamy N, Velineni S, Donahue JM, Artiushin SC, Fettinger M (2011) A unique genotype of Leptospira interrogans serovar Pomona type kennewicki is associated with equine abortion. Veterinary Microbiology 150: 349-353.

Tsegay K, Potts AD, Aklilu N, Lotter C, Gummow B (2016) Circuling serovars of Leptospira in cart horses of central and southern Ethiopia and associated risk factors. Preventive Veterinary Medicine 125: 106-115. doi: 10.1016/j.prevetmed.2016.01.009.

Verma A, Artushin S, Matsunaga J, Haake DA, Timoney JF (2005) LruA and LruB, novel lipoproteins of pathogenic Leptospira interogans associated with equine recurrent uveitis. Infection and Immunology 73: 7259-7266. doi: 10.1128/IAI.73.11.7259-7266.2005

Verma A, Kumar P, Babb K, Timoney JF, Stevenson B (2010) Cross- reactivity of antibodies against leptospiral recurrent uveitis-associated proteins A and B (LruA and LruB) with eye proteins. PLoS Neglected Tropical Diseases 4 e778. doi.org/10.1371/journal.pntd.0000778

Verma A, Stevenson B, Alder B (2013) Leptospirosis in horses. Veterinary Microbiology 167: 61-66. doi: 10.1016/j.vetmic.2013.04.012

Vinetz J (1997) Leptospirosis. Current Opinion in Infectious Diseses 10: 357-361.

Vinetz JM, Glass GE, Flexner CE, Mueller P, Kaslow DC (1996) Sporadic urban leptospirosis. Annals of Internal 
Medicine 125: 794-798. doi: 10.7326/0003-4819-125-10199611150-00002

Wada S (2006) Changes of intraocular pressure in uveitic horses, Journal of Equine Science 17: 67-73.

Werry H, Gerhards H (1991) Moglichkeiten der und indikationen zur chirurgishen behandlung der euinen rezidivierenden uveitis (ERU). Pferdeheikunde 7: 321-331.

Whitcup SM (2010) Anterior uveitis. In: Nussenblatt RB, Whitcup SM (Eds.) Uveitis. Fourth Ed. Mosby Elsevier. pp. 251-263.

Williams RD, Morter RL, Freeman MJ, Lavignet A (1971) Experimental chronic uveitis- ophthalmic signs following equine leptospirosis. Investigative Ophthalmology 10: 948 954.
Wilkie IW, Prescott JF, Hazlett MJ, Maxie MG, van Dreumel AA (1988) Giant cell hepatitis in four aborted foals: A possible leptospiral infection. Canadian Veterinary Journal 29: 10031004.

Witkowski L, Cywinska A, Paschalis-Trela K, Crisman M, Kita J (2016) Multiple etiologies of equine recurrent uveitis_ A natural model for human autoimmune uveitis: A brief review. Comparative Immunology, Microbiology and Infectious Diseases 44: 14-20. doi: 10.1016/j.cimid.2015.11.004

Ye C, Yan W, McDonough PL, McDonough SP, Mohamed H, Divers TJ, Chang YF, Yang Z (2014) Serodiagnosis of equine leptospirosis by enzyme-linked immunosorbent assay using four recombinant protein markers. Clinical and Vaccine Immunology $21: 478-83$. 